a consistent finding, it did it seem to impact their health status adversely.

Inevitably this well conducted trial will raise some further questions. The patients included here were less severe, as judged by their postbronchodilator lung function, than in other recent COPD studies (mean $\mathrm{FEV}_{1} 52 \%$ predicted here). They appeared to have a greater degree of reversibility than reported in other COPD trials, although the absolute lung function changes are difficult to calculate from the data given and are unlikely to be as great as the numbers based on a percentage change from baseline would suggest. ${ }^{17}$ Over half of the patients were using inhaled corticosteroid during the trial and it would be interesting to know whether some of the clinical outcomes, such as the improvement in breathlessness or the exacerbation frequency, showed any interaction between this background treatment and the new drugs. Certainly, the exacerbation rate was lower than in other studies, perhaps reflecting the selection criteria or the use of concomitant medication. Similar problems have been seen when the effects of combination of treatments with monotherapy with long-acting $\beta$-agonists on these clinical outcomes have been compared in similar 1 year studies. ${ }^{18}$ However, the data showing superiority of indicaterol to formoterol in terms of lung function are very convincing. Direct comparisons between indicaterol and longacting antimuscarinic agents such as tiotropium will be awaited with interest and should resolve the long-standing question of whether drugs targeted to block or stimulate specific pathways moderating airway smooth muscle function do produce different responses in patients with COPD. Likewise it will be important to establish whether there are advantages in combining once-daily $\beta$-agonists with once-daily inhaled corticosteroids, which can also have clinical effects in COPD, ${ }^{19}$ when compared with existing twice-daily regimes. For now we can be assured that long-acting inhaled $\beta$-agonists have arrived, are effective and offer the prospect of simpler treatment for our patients.

Competing interests I have advised and led clinical trials of bronchodilator therapy for several companies including GSK, Boehringer Ingelheim and AstraZeneca. I have advised Noartis, the study sponsors, on study design and serve on a data safety monitoring board for another trial they are running in COPD.

Provenance and peer review Commissioned; not externally peer reviewed.

Thorax 2010;65:468-469.

doi:10.1136/thx.2009.130211

\section{REFERENCES}

1. Rabe KF, Hurd S, Anzueto A, et al. Global strategy for the diagnosis, management, and prevention of chronic obstructive pulmonary disease: GOLD executive summary. Am J Respir Crit Care Med 2007:176:532-55.

2. National Emphysema Treatment Trial Research Group. A randomized trial comparing lung-volume reduction surgery with medical therapy for severe emphysema. N Engl J Med 2003;348:2059-73.

3. Calverley PM, Anderson JA, Celli B, et al Salmeterol and fluticasone propionate and survival in chronic obstructive pulmonary disease. N Engl J Med 2007;356:775-89.

4. Calverley PM, Rabe KF, Goehring UM, et al. Roflumilast in symptomatic chronic obstructive pulmonary disease: two randomised clinical trials. Lancet 2009;374:685-94.

5. Fabbri LM, Calverley PM, Izquierdo-Alonso JL, et al. Roflumilast in moderate-to-severe chronic obstructive pulmonary disease treated with longacting bronchodilators: two randomised clinical trials. Lancet 2009;374:695-703.

6. Anon. Routine nebulized ipratropium and albuterol together are better than either alone in COPD. The
COMBIVENT Inhalation Solution Study Group. Chest 1997;112:1514-21.

7. Jones PW, Bosh TK. Quality of life changes in COPD patients treated with salmeterol. Am J Respir Crit Care Med 1997;155:1283-9.

8. Dahl R, Greefhorst LA, Nowak D, et al. Inhaled formoterol dry powder versus ipratropium bromide in chronic obstructive pulmonary disease. Am J Respir Crit Care Med 2001;164:778-84.

9. Mahler DA, Donohue JF, Barbee RA, et al. Efficacy of salmeterol xinafoate in the treatment of COPD. Chest 1999; 115:957-65.

10. Stockley RA, Chopra N, Rice L. Addition of salmeterol to existing treatment in patients with COPD: a 12 month study. Thorax

2006;61:122-8

11. Calverley PM, Lee A, Towse L, et al. Effect of tiotropium bromide on circadian variation in airflow limitation in chronic obstructive pulmonary disease. Thorax 2003:58:855-60.

12. Vincken W, Van Noord JA, Greefhorst AP, et al. Improved health outcomes in patients with COPD during 1 yr's treatment with tiotropium. Eur Respir $J$ 2002;19:209-16.

13. Tashkin DP, Celli B, Senn S, et al. A 4-year trial of tiotropium in chronic obstructive pulmonary disease. N Engl J Med 2008;359:1543-54.

14. Brusasco V, Hodder R, Miravitlles M, et al. Health outcomes following treatment for six months with once daily tiotropium compared with twice daily salmeterol in patients with COPD. Thorax 2003;58:399-404

15. Rennard S, Bantje T, Centanni S, et al. A doseranging study of indacaterol in obstructive airways disease, with a tiotropium comparison. Respir Med 2008; 102:1033-44.

16. Dahl R, Chung KF, Bull R, et al. Efficacy of a new once-daily long-acting inhaled $\beta_{2}$-agonist indacaterol versus twice-daily formoterol in COPD. Thorax 2010;65:473-9

17. Calverley PM, Burge PS, Spencer S, et al. Bronchodilator reversibility testing in chronic obstructive pulmonary disease. Thorax 2003;58:659-64.

18. Calverley P, Pauwels R, Vestbo J, et al. Combined salmeterol and fluticasone in the treatment of chronic obstructive pulmonary disease: a randomised controlled trial. Lancet 2003;361:449-56.

19. Calverley PM, Rennard S, Nelson HS, et al. One-year treatment with mometasone furoate in chronic obstructive pulmonary disease. Respir Res 2008; 9:73

\title{
Respiratory disease in 2010: looking to the past will prepare us for the future
}

\section{David M Mannino}

Correspondence to David M Mannino, Department of Preventive Medicine and Environmental Health, University of Kentucky College of Public Health, 121 Washington Avenue, Lexington, KY 40536, USA; dmannino@uky.edu
Hanging on the wall in my office are two obituaries, one of Dr Charles Fletcher who died in $1995^{1}$ and the other of Dr Benjamin Burrows who died in 2002. ${ }^{2}$ Their pictures look over the desk where I do a great deal of my work and provide inspiration and, through their collective body of work, guidance. I would like to think that the work that I do continues in a very small way the work that these giants in our field started. Dr Fletcher was responsible for, among other accomplishments, defining the natural history of chronic obstructive pulmonary disease in his landmark study of British men. ${ }^{3-5}$ Dr Burrows founded the Tucson Epidemiological Study of Airway Obstructive Disease (TESAOD) ${ }^{6}$ that has added greatly to our knowledge of respiratory disease. Drs Fletcher and Burrows trained and mentored many of our current leaders in respiratory health and coauthored several publications. ${ }^{78}$ An ongoing legacy 
of Dr Burrows is the TESAOD, which continues to provide valuable and important information relevant to today.

The publication by Guerra et al in this issue of Thorax (see page 499) provides an example of Dr Burrows' ongoing legacy and the convergence of his work with that of Dr Fletcher in trying to better understand the natural history of lung disease. ${ }^{9}$ This analysis of the TESAOD data examined the baseline lung function, changes in lung function over the next 25 years of the study and the effects of lung function on mortality by year 34 of the study. The traditional view of the natural history of lung disease dating back to the time of Dr Fletcher has focused on lung function decline-the idea that, with each passing year, people lose some of their forced expiratory volume in $1 \mathrm{~s}$ and those who lose this more quickly develop chronic obstructive pulmonary disease (COPD). ${ }^{3} \quad 10 \quad 11$ This construct has provided the basis for the main paradigms by which we attempt to determine COPD progression and the effectiveness of treatment. ${ }^{10} 12 \quad 13$ Ironically, though, the concept of 'lung function decline' is not terribly useful clinically. We know that an individual's lung function and reversibility testing can vary dramatically from day to day and even from test to test on the same day. ${ }^{14} 15$ Over the years I have made almost no clinical decisions in my patients with COPD on the basis of 'accelerated decline in lung function'. Rather, I have categorised patients' lung function, asked about their symptoms and exacerbations, and determined interventions based on the information gathered.

In the paper by Guerra et al, not one analysis attempts to determine lung function decline. ${ }^{9}$ Rather, the authors classify subjects as obstructed or 'restricted' at baseline and follow-up visits and use these more clinically relevant categories to predict outcomes. This approach raises several issues, especially with regard to the 'restrictive spirometric' pattern. From the time of Hutchinson, clinicians have known that a low lung capacity resulted in a shorter life-this represents the origin of the term 'vital vapacity'. ${ }^{16}$ In recent years the links between restrictive spirometric patterns and diabetes, ${ }^{17}$ heart failure, ${ }^{18}$ lung cancer, $^{19}$ asthma $^{20}$ and obesity ${ }^{21}$ have been explored. In a large study from the Mayo Clinic ${ }^{22}$ there is even evidence that this pattern can represent a subtype of COPD in some cases, with the thought process being that air trapping resulting in a smaller forced vital capacity may be one of the initial manifestations of COPD. Of course, there are a host of other problems that can result in this pattern, ranging from muscle weakness to poor effort. Furthermore, the presence of a restrictive pattern, regardless of the aetiology, predicts worse outcomes such as deaths and hospitalisations. ${ }^{23}$ This was confirmed in the analysis by Guerra et al of the TESAOD cohort. ${ }^{9}$

Guerra et al, however, took their analysis one step further by looking at longitudinal changes in lung function. ${ }^{9}$ To accomplish this, rather than looking at lung function decline they examined what category the person was in at the time of the testing (obstructive or restrictive) and further classified them into one of six categories based on this pattern over time. The bottom line was that the presence of a restrictive pattern in just one of the evaluations predicted an increased risk in mortality that was similar in magnitude to that seen with 'recurrent obstruction' or COPD.'

The hallmark of the work of both Dr Fletcher and Dr Burrows was that they challenged the norms of their day and were willing to create new paradigms to advance medical knowledge and result in better interventions for our patients. Is it time for a new paradigm for chronic lower respiratory diseases (to include the various subtypes of asthma, COPD and restrictive lung diseases)? I believe it is! Moving away from Dr Fletcher's paradigm of 'lung function decline' to one that includes transitions between spirometric categories, radiographic data, cormorbid disease and, eventually, genomic, proteonomic and metabalomic information, is a change that I'm confident both Dr Fletcher and Dr Burrows would have happily embraced. Of course, this task will not be an easy one, but the tasks that Drs Fletcher and Burrows met head on and conquered in their day were, in many ways, more challenging than what we face today. Their biggest challenge was that they did not have the body of work of these giants in our field to rely on. As we prepare for the future, I encourage all researchers to study the work of these and other historic leaders in our field and, as they did, to keep an open mind, to challenge the status quo and to keep the ultimate goal of improving the lives of our patients central to our work.

Competing interests DMM has received research funding from GlaxoSmithKline, Novartis and Pfizer Pharmaceuticals and has served as a consultant or speaker for AstraZeneca, GlaxoSmithKline, Pfizer, Novartis, Forest and Boerhinger-Ingelhiem
Pharmaceuticals. He is also on the Board of Directors of the USCOPD Coalition and the COPD Foundation.

Provenance and peer review Commissioned; not externally peer reviewed.

Thorax 2010;65:469-471

doi:10.1136/thx.2010.137570

\section{REFERENCES}

1. Anon. Obituary of Charles Fletcher. BMJ 1996:312:117.

2. Postma DS, Pride N, Viegi G. Benjamin Burrows, MD, 1927-2002. Eur Respir J 2003;21:200.

3. Fletcher $\mathbf{C}$, Peto $\mathrm{R}$, Tinker $\mathrm{CM}$, et al. The natural history of chronic bronchitis and emphysema. Oxford: Oxford University Press, 1976.

4. Fletcher $\mathbf{C}$, Peto R. The natural history of chronic airflow obstruction. BMJ 1977:1:1645-8.

5. Fletcher C. Conversation with Charles Fletcher. $\mathrm{Br} \mathrm{J}$ Addict 1992;87:527-38

6. Lebowitz MD, Knudson RJ, Burrows B. Tucson epidemiologic study of obstructive lung diseases. I: Methodology and prevalence of disease. Am J Epidemiol 1975;102:137-52.

7. Burrows B, Fletcher CM, Heard BE, et al. The emphysematous and bronchial types of chronic airways obstruction. A clinicopathological study of patients in London and Chicago. Lancet 1966:1:830-5.

8. Jones NL, Burrows B, Fletcher CM. Serial studies of 100 patients with chronic airway obstruction in London and Chicago. Thorax 1967:22:327-35.

9. Guerra S, Sherrill DL, Venker C, et al. Morbidity and mortality associated with the restrictive spirometric pattern: a longitudinal study. Thorax 2010;65:499-501.

10. Anthonisen NR, Skeans MA, Wise RA, et al. The effects of a smoking cessation intervention on 14.5year mortality: a randomized clinical trial. Ann Intern Med 2005;142:233-9.

11. Kohansal R, Martinez-Camblor P, Agusti $A$, et al. The natural history of chronic airflow obstruction revisited: an analysis of the Framingham offspring cohort. Am J Respir Crit Care Med 2009; 180:3-10.

12. Calverley PM, Anderson JA, Celli B, et al. Salmeterol and fluticasone propionate and survival in chronic obstructive pulmonary disease. N Engl J Med 2007;356:775-89.

13. Decramer $\mathbf{M}$, Celli B, Tashkin DP, et al. Clinical trial design considerations in assessing long-term functional impacts of tiotropium in COPD: the UPLIFT trial. COPD 2004;1:303-12

14. Pennock BE, Rogers RM, McCaffree DR. Changes in measured spirometric indices. What is significant? Chest 1981;80:97-9.

15. Calverley PM, Burge PS, Spencer S, et al. Bronchodilator reversibility testing in chronic obstructive pulmonary disease. Thorax 2003 ; 58:659-64

16. Petty TL. John Hutchinson's mysterious machine revisited. Chest 2002;121:219-23S.

17. Ford ES, Mannino DM. Prospective association between lung function and the incidence of diabetes: findings from the National Health and Nutrition Examination Survey Epidemiologic Follow-up Study. Diabetes Care 2004:27:2966-70.

18. Diaz-Guzman E, McCarthy K, Siu A, et al. Frequency and causes of combined obstruction and restriction identified in pulmonary function tests in adults. Respir Care 2010;55:310-16.

19. Purdue MP, Gold L, Jarvholm B, et al. Impaired lung function and lung cancer incidence in a cohort of Swedish construction workers. Thorax 2007:62:51-6. 
20. Miller A, Palecki A. Restrictive impairment in patients with asthma. Respir Med 2007;101:272-6.

21. Fimognari FL, Pasqualetti $P$, Moro $L$, et al. The association between metabolic syndrome and restrictive ventilatory dysfunction in older persons. J Gerontol A Biol Sci Med Sci 2007:62:760-5

22. Hyatt RE, Cowl CT, Bjoraker JA, et al. Conditions associated with an abnormal nonspecific pattern of pulmonary function tests. Chest 2009;135:419-24.
23. Mannino DM, Doherty DE, Buist AS. Global Initiative on Obstructive Lung Disease (GOLD) classification of lung disease and mortality: findings from the Atherosclerosis Risk in Communities (ARIC) study. Respir Med 2006;100:115-22.

\section{Impact of the 2009 influenza pandemic}

\section{J Dunning, P J M Openshaw}

\section{A GENERALLY MILD DISEASE THAT SOMETIMES KILLED}

One year on from the start of the 21st century's first influenza pandemic, it is a good time to take stock of how the outbreak evolved and what has been learned. Although we now know that many infections were mild or inapparent, it is important not to forget the severe disease that it sometimes caused, and may still cause, in future winters.

During April 2009, reports from Mexico provided a worrying picture of unusually severe influenza in large numbers of healthy people including healthcare workers. ${ }^{1}$ The impact on hospitals was particularly marked with up to one in four specialist beds being occupied by patients with influenza, often needing highly specialised care and mechanical ventilation. Medical resources were exceeded by demand, and elective admissions and surgery halted; transmission to staff and to other patients was common, placing specialised nursing care, consumables, ventilators, drugs and containment facilities under great pressure.

Once cases began to appear in UK schools in May 2009, an intensive cooperative campaign of quarantine and antiviral prophylaxis was mounted by the Heath Protection Agency, the Department of Health and the NHS. Antiviral drugs have not been used in this way in previous pandemics; although it was unlikely that the spread of influenza could be halted, it was important to gather information about the pattern and severity of disease and to slow the spread, buying time for vaccine development and capacity building.

Imperial College London, London, UK

Correspondence to Professor P J M Openshaw, Imperial College London, St Mary's Campus, Respiratory Medicine, Norfolk Place, London W2 1PG, UK; p.openshaw@imperial.ac.uk
Despite the public health campaign, the numbers of cases increased in London and the West Midlands, putting considerable strain on primary care. By 2 July, case numbers were rising sharply in most parts of the UK and containment measures no longer seemed appropriate. Routine antiviral prophylaxis was discontinued and a telephone helpline was launched on 23 July. ${ }^{2}$ Call centres took a history according to defined algorithms and authorised antiviral treatment for those with appropriate symptoms. Case numbers declined rapidly soon after schools broke up for the summer holidays in late July, with a second autumn wave occurring after children returned to school in September.

The impact of the outbreak on hospitals was considerable. Pandemic (H1N1) 2009 Influenza (pH1N1) spread predominantly among children and young adults, causing severe disease in some vulnerable adults (particularly patients with asthma, those with various chronic illnesses and pregnant women). In the first week of November there were approximately 850 patients hospitalised with confirmed pH1N1, 20\% of whom required critical care. The worst recent daily estimate was at the height of the second wave (4 November) with 172 patients hospitalised in critical care and 848 patients hospitalised overall. Provisional data from a retrospective analysis of hospital admissions in the UK indicated that influenza-associated bed-days increased from 4163 in 2008 to 33376 in 2009, about a sevenfold rise. In those aged $17-39$ years of age the increase was from 169 to 6253 in the October to December period, an extraordinary 37 -fold increase. ${ }^{3}$ Fortunately, the number of confirmed UK deaths remains at 474, which is fewer than feared. ${ }^{4}$

The report by Fajardo-Dolci et al in this issue of Thorax describes the characteristics of the first 100 consecutive fatalities due to pH1N1 during Mexico's first wave of the pandemic (see page 505). ${ }^{5}$ This is a particularly important study since it describes influenza-related deaths occurring close to the source of the pH1N1 outbreak, presumed to be in southern USA or Mexico. This study highlights several important features about pH1N1-related deaths that generally mirror those seen elsewhere across the globe ${ }^{6-8}$ Although the Mexican deaths were often in previously healthy people, metabolic syndrome, cardiovascular disease and chronic respiratory disease were identified as risk factors associated with high mortality. Obesity seems to be an important risk factor for hospital admission, but not necessarily for death. ${ }^{9}$

Although the relative contribution of individual at-risk groups appears to vary from country to country, the overall message so far appears to be that, when pH1N1 does kill, the majority who die are young to middle-aged adults with comorbidities, although $10-20 \%$ of those who died were previously healthy. pH1N1 tended to cause viral pneumonitis and acute lung injury, but antibiotic use was frequent in Mexico (as it was in many other countries). While sometimes complicated by bacterial pneumonia, confirmation of bacterial coinfection prior to death remains significantly lower than that described in the limited post-mortem series, although this may reflect how bacterial coinfection is both investigated and defined. ${ }^{10-12}$

It is also notable that almost $60 \%$ of cases described by Fajardo-Dolci et al received steroids, although it is not clear how many received high-dose corticosteroids, how many received steroids for adrenal support in sepsis and what proportion required continuation of preexisting steroid treatment. The role of steroids in both the pathogenesis and potential treatment of viral pneumonitis remains unclear, but many authorities advise against routine use of high-dose steroids in viral pneumonitis based on experience with the management of SARS and $\mathrm{H} 5 \mathrm{~N} 1$ infection. ${ }^{13}$

Notably, Fajardo-Dolci et al reported that $>80 \%$ of patients developed symptoms before a national influenza alert was issued. Local populations and healthcare providers may not therefore have been in 